\title{
A essência da linguagem
}

V. 1 - N. 2 -

$2^{\circ}$ Semestre de 2011

* Editor da Teoliterária 
Prince de Saint-Exupéry: "Le langage est source de malentendus" o que se exige que a cada dia "se sente um pouco mais perto" [ $t$ 'assesoir un peu plus près... $]^{1}$.

De modo muito parecido o filósofo alemão Martin Heidegger ao se perguntar pela essência da linguagem refletindo quer sobre as "marcas escritas" ou os "sons da voz" indica que a linguagem constitui "símbolos das disposições da alma" ${ }^{2}$ e, portanto, a essência da linguagem indica nada mais que a linguagem da essência, entendendo por "essência" o "universal", "o que vale para toda e qualquer coisa"3 de modo que não nos basta uma explicação lógico-racional da linguagem e uma "determinação do significado das palavras exclusivamente como conceitos"4 mas há que se procurar uma "experiência com a linguagem" pois o logos diz respeito ao dizer e ao ser, ou seja, no ser da linguagem se esconde o mistério de sentido da existência humana a ser desvendado, o enigma da vida de cada um.

E aqui é a poiésis que permite a experiência da linguagem pois desvela aquilo que é por demais digno de pensar como "experiência da proximidade com aquilo que nos revoluciona" ao permitir um encontro "face a face" com as coisas em estado de poesia, para lembrar Goethe ${ }^{6}$.

Deste modo, para citar Eliana Yunes ${ }^{7}$ :

A literatura, como todo discurso artístico (mas não só), inscreve-se em um plano deslocado em relação à estrutura do discurso ordinário. Dizê-lo extraordinário não é concebê-lo

1. SAINT-EXUPÉRY, Antoine. Le Petit Prince. Editions Gallimard, 1999, p. 73.

2. HEIDEGGER, Martin. A Caminho da Linguagem. Petrópolis: Editora Vozes/Bragança Paulista: Ed. Universitária São Francisco, 2011, p. 160.

3. Idem, p. 7.

4. Idem, p. 11

5. Idem, p. 170 .

6. VAZSONYI, Nicholas. Lukács reads Goethe: from aestheticism to Stalinism. Columbia: Camden House, 1997, p. 12

7. YUNES, Eliana. O Sentido ao Pé das Letras In AVZARADEL, José Renato (org.) Linguagem e Construção do Pensamento. São Paulo: Casa do Psicólogo, 2006, p. 272. 
como produção de gênio, ao modo romântico de perceber a criação humana. $\mathrm{O}$ discurso literário tem um modo próprio de perscrutar o mundo e o homem, vizinho da filosofia, mas na contramão de sua prática analítica e lógica. De modo econômico e denso, o literário expõe o que permanece velado, em forma que se quer bela, seja isto o que for, segundo tempos e culturas. Por conta deste descentramento, a produção literária, por outro lado, é aparentada do discurso mi(s)tico que instala um lugar de dissonâncias e vazios, ao mesmo tempo em que procura recobri-lo, com o verbo manejado em uma rede sintático-semântica imprevisível segundo as gramáticas [...] O literário, enquanto expressão verbal, tanto partilha a busca de humano conhecimento quanto encena o dizer que ultrapassa o horizonte deste saber.

Sendo assim, o dizer literário, muito próximo a mística, que segue outras razões, como que mapeando as "disposições da alma" em uma espécie de discernimento do que nos move, para lembrar a mística de Inácio de Loyola ou de uma filosofia da vontade em Paul Ricoeur como hermenêutica dos afetos que encontra seu espelho nos textos literários, de modo não só a entender o texto, mas a se entender diante do texto, faz uso da linguagem religiosa como possibilidade de tradução destas disposições interiores, ou seja, a literatura faz uso da linguagem teológica em uma perspectiva existencial e não meramente conceitual.

Ao assim fazer, salva a teologia do nominalismo do século XIV em que os signos ocupam o lugar da coisas de modo que o ato mental se concentrasse nos conceitos; ou ainda do racionalismo que tratou o discurso (oratio) como conexão de nomes que afirma ou nega a partir do raciocínio, tido como cálculo de demonstração do conhecimento matemático das causas dos fatos, para pensar em Hobbes, por exemplo (De Corpore I,3,1). Ideias, entre outras, que geraram a concepção de uma "teologia científica" que pretendia provar a existência de Deus.

Tal teologia de afirmações e negações do sic et non (assim e não assim) é criticada por um grande teólogo alemão do século XX, Karl Rahner, de modo que "não se deve identificar o mistério com afirmação [Satz] que 
não tenha sentido [sinnlos] para nós" para pensar o que viria a ser uma "existência cristã" [Christ sein] no indivíduo hodierno e as manifestações não-científicas da vida como a arte e a poesia, vistas pelo teólogo alemão como "formas do espírito [Gestalt des Geistes] e da autocompreensão humana [menschlichen Selbstverständnisses]" em que a teologia deve se ocupar $^{8}$.

Essa orientação da teologia que emerge da antropologia, ou seja, da existência em busca de sentido, retoma necessariamente suas raízes místicas e com isso a unidade fundamental entre ato intelectivo e ato amoroso ou afetivo, preservado inclusive em São Tomás de Aquino. Em outras palavras não se pode conhecer a Deus sem conhecer sua essência que é amor, contudo, não se limitando a conceituar essa essência, mas antes pode constatar por meio da mimesis literária o quanto ainda não se ama ou não se está aberto ao amor.

Entretanto, a missão do poeta e do literato para Nikos Kazantzákis não se limita a salvar a teologia, mas antes os autores são salvadores de Deus do racionalismo, para dar voz aos anseios mais profundos do ser humano ouvidos em uma teologia do coração marcada pela ascese poética da linguagem ${ }^{9}$ :

Ouço uma ordem dentro de mim:

- Cava! Que vês?

- Homens e aves, águas e pedras!

- Cava mais! Que vês?

- Ideias e sonhos, relâmpagos e fantasmas.

- Cava mais! Que vês?

- Não vejo coisa alguma! Só a Noite, muda e espessa como a morte. Deve ser a morte.

- Cava, cava!

- Ai, não posso atravessar a muralha negra! Ouço vozes e prantos, ouça bater de asas do outro lado!

- Não chores! Não chores! Não é do outro lado! As vozes, os

8. RAHNER, Karl. Grundkurs des Glaubens - Einführung in den Begriff des Christentums. Freiburg/Basel/Wien: Herder Verlag, 2004, p. 13.20-23

9. KAZANTZÁKIS, Nikos. Segundo Dever In Ascese - Os Salvadores de Deus. Ed. Ática, 1997. 
prantos e o bater de asas são o teu coração!

Na ponta dos pés, vou além da mente e chego trêmulo ao sagrado abismo do coração. Um dos pés se apóia no chão firme, o outro tateia as trevas do abismo.

Suspeito que atrás de todas as aparências há uma essência em luta. Quero unir-me a ela.

Suspeito que a essência em luta busca também, atrás das aparências, unir-se ao meu coração.

Assim a presente edição da Teoliteraria deseja explorar essas possibilidades de experimentar a linguagem que nos aproxima de nosso eu mais profundo. O artigo de Jimmy Sudario Cabral, da Universitè de Strasbourg apresenta bem como a poiésis do Evangelho foi sendo gestada através da tecitura social de Israel provocando uma mudança de imagem da realidade que retroalimenta uma mudança na percepção do que se poetiza como imagem de Deus. Ricardo Taurisano, da Universidade de São Paulo, colabora apresentando como vai se formando uma retórica religiosa cristã como linguagem que deseja apresentar a Verdade. Carmem Lussi, da Pontifícia Universidade Católica do Rio de Janeiro, apresenta a contribuição de Karl Rahner a respeito da linguagem poética e literária em que acontece como experiência do mistério na existência. E Marco Polermo, da Pontifícia Universidade Católica de São Paulo, apresenta a partir da linguagem poética de Adélia Prado, a expressão da experiência do eulírico com o sagrado.

Nos demais artigos, Laura Gávilán, da Universidad de Buenos Aires mostra como a linguagem religiosa não somente não está imune de seu contexto social e político, como não raro intercambiam os esquemas de interpretação como na literatura de Coleridge que descreve a Revolução Francesa como um acontecimento divino. Antonio Geraldo Cantarela, da Pontifícia Universidade Católica de Minas Gerais, enfoca na obra do poeta moçambicano Mia Couto como os nomes-personagens do autor decifram o Numinoso de inesgotável dizer a partir da condição marginal do ser humano onde se explicíta um projeto literário teologizável de com- 
promisso político. Luzia Toffalini, da Universidade Estadual de Maringá, se utiliza da obra prima do escritor português Raul Germano Brandão, a saber Húmus, em sua metafísica do não-ser. De outra forma, Cleide Oliveira, da Universidade Federal do Rio de Janeiro, a partir da poesia de Manuel de Barros procura uma aproximação da mística apofática em uma espécie de poesia negativa onde se procura a essência na escuridão, no vazio, no deserto, ou seja, na oscuridade, na inutilidade e na desinvenção das certezas definidas.

Ainda nesta edição inauguramos nas Notas Bibliográficas, um espaço para ensaios de teologia e literatura para as pesquisas produzidas já na graduação. Esse é o caso de Flávio Honório da Silva do Instituto de Teologia de São Paulo (ITESP) e o paralelo que procura traçar no conceito de anomia em Memórias do Subsolo de Dostoiévski e a ideia de pecado social e sua necessidade de consciência responsável e abertura para o amor como sinônimo existencial de salvação. Também Mateus Domingues da Silva, OP da Escola Dominicana de Teologia (EDT) traça um paralelo entre o Riso e a Esperança no pensamento de Ernest Bloch.

Benedito Prézia da Pontifícia Universidade Católica de São Paulo, apresenta um belíssima resenha do trabalho que organizou sobre a poética indígena a respeito da criação do mundo.

Por fim entrevistamos a Profa. Eliana Yunes, atual presidente da ALALITE a respeito das atividades dessa associação internacional e do IV Colóquio que irá acontecer em 2012 em São Paulo.

Também a partir desta edição gostaríamos de apresentar a página "Livros" na Teoliterária que visa apresentar a obra de diversos autores que pesquisam em Teologia e Literatura e que queiram divulgar seus trabalhos.

Encerramos assim nossa segunda edição e o ano de 2011, agradecen- 
do a todos aqueles que de algum modo ajudaram no surgimento e desenvolvimento da Teoliterária. Desejamos a todos, novas inspirações para iniciar um ano novo, novamente no mesmo tempo de todos os tempos e ao mesmo tempo, o novo de novo. 